\title{
Article
}

\section{Missing children: risks, repeats and responses}

Sidebottom, Aiden, Boulton, Laura, Cockbain, Ella, Halford, Eric and Phoenix, Jessica

Available at http://clok.uclan.ac.uk/30220/

Sidebottom, Aiden, Boulton, Laura ORCID: 0000-0001-5623-8884, Cockbain, Ella, Halford, Eric and Phoenix, Jessica (2019) Missing children: risks, repeats and responses. Policing and Society. ISSN 1043-9463

It is advisable to refer to the publisher's version if you intend to cite from the work. http://dx.doi.org/10.1080/10439463.2019.1666129

For more information about UCLan's research in this area go to

http://www.uclan.ac.uk/researchgroups/ and search for < name of research Group>.

For information about Research generally at UCLan please go to http://www.uclan.ac.uk/research/

All outputs in CLoK are protected by Intellectual Property Rights law, including Copyright law. Copyright, IPR and Moral Rights for the works on this site are retained by the individual authors and/or other copyright owners. Terms and conditions for use of this material are defined in the policies page.

\section{CLoK}

Central Lancashire online Knowledge www.clok.uclan.ac.uk

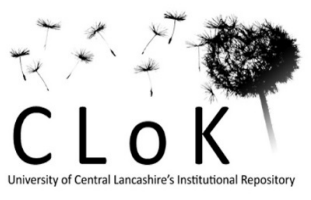




\section{Policing \& Society \\ Routledge \\ Q Taylor \& Francis Group}

\section{Missing children: risks, repeats and responses}

\begin{tabular}{|r|l|}
\hline Journal: & Policing \& Society \\
\hline Manuscript ID & Draft \\
\hline Manuscript Type: & Original Article \\
\hline Keywords: & missing, children, repeats, police \\
\hline &
\end{tabular}

SCHOLARONE"
Manuscripts 


\section{Introduction}

Investigating reports of missing persons is a longstanding challenge for the police in the UK, for two main reasons. The first is the volume of missing person incidents. In 2015/16, for example, more than 130,000 children and adults were reported missing in England and Wales; the equivalent of 662 reports per dayi. Second is the diversity of missing person reports. In the UK, the police define a missing person as 'anyone whose whereabouts cannot be established where the circumstances are out of character or the context suggests the person may be the subject of crime or at risk of harm to themselves or another' (ACPO, 2013, p. 5). In practice, the term 'missing persons' refers to a heterogeneous group of people whose vulnerability may be exacerbated by factors associated with their age, neglect, exploitation and abuse, mental illness or suicide risk. It covers, for example, adults who go missing for reasons of financial hardship, teenagers running away from residential care, children who are abducted, individuals missing in the wake of a disaster and persons who are simply waylaid or disoriented. Variation in the motivation behind and circumstances of missing incidents can make it challenging to ascertain a proportionate police response (Fyfe et al. 2015) - all the more so if the available information is limited. Thus, although the vast majority of missing persons are located safely and within 24 hours (see Holmes, 2017), the police must respond with the knowledge that a small number of missing person cases involve an immediate threat to life (Newiss, 1999).

The police costs associated with missing persons are substantial (Shalev Greene and Pakes, 2013). The UK College of Policing (COP, 2015) estimate that the police in England and Wales devote around 3.3 million 'investigation hours' per year on missing persons. Recent estimates 
place the annual police cost between $£ 394$ million and $£ 509$ million (Babuta and Sidebottom, 2018). Furthermore, the costs associated with missing persons go beyond the economic. To be reported missing is to be missed. Henderson et al. (2000) suggest that for every person missing, a further 12 individuals are affected. Qualitative studies demonstrate the significant emotional and physical impact of a loved one going missing (Holmes, 2008). As Wayland observes, 'families respond in similar ways to those exposed to a sudden trauma: shock, distress, confusion, ambivalence and a considerable sense of being overwhelmed' (2007, p. 11).

Our focus here is on children and young people who go missing. Throughout the paper we use the term children to refer to those aged under 18, in accordance with the United Nations' Convention on the Rights of the Child. Police data for England and Wales indicate that around $60 \%$ of all missing person incidents involve children (NCA, 2016). Similar patterns are observed in Australia (Bricknell and Renshaw, 2016), Canada (Government of Canada, 2017) and Scotland (Police Scotland, 2018). Moreover, the police place a high priority on the investigation of missing children in part because of emerging evidence that going missing is both a potential indicator of underlying vulnerabilities (Hayden and Shalev Greene, 2018) and a risk factor for abuse (Sharp-Jeffs, 2016; Simon, Setter and Holmes, 2016), health-related harm (Whitbeck et al. 2007) and youth offending (Heerde et al. 2014). It forms part of the police 'duty of care', enshrined in the Human Rights Act 1998, to 'safeguard the rights of individuals who may be at risk' (ACPO, 2010, p. 15).

Some children go missing more frequently than others. Presently, however, the prevalence and patterns of repeat disappearances of children have received limited research attention 
(exceptions include Shalev-Greene, 2011 and Babuta and Sidebottom, 2018). The current study seeks to address this gap and contribute to the limited evidence-base concerning (repeatedly) missing children. The analyses that follow draw on prior research, theory and practice concerned with the patterns and prevention of repeat victimisation (see Farrell, 1995; Pease, 1998; Farrell and Pease, 2017), with particular focus on work which demonstrates that crime is unevenly distributed across victims (Farrell, 1995; Pease, 1998) and that the risk of being a repeat victim is elevated in the immediate period following victimisation and decays over time (see Chenery et al. 1997; Polvi et al. 1990; Sagovsky and Johnson, 2007; Townsley et al. 2000). Going missing is clearly neither a crime nor a form of victimisation. Rather, in this paper we take a similar analytical approach to that which has examined repeat victimisation, and use it to explore three hitherto understudied research questions in the missing persons literature. First, how prevalent are repeat missing incidents involving children (defined here as two or more police recorded missing episodes in a one year period)? Second, what factors are associated with a child repeatedly going missing? And third, what is the time course of repeat disappearances by children, measured here as the time elapsed between a child's first and second missing episode? This paper is, to the best of our knowledge, the first to examine the time-to-repeat for missing children.

The remainder of this paper is divided into four sections. The first section reviews the literature on children who repeatedly go missing. The second section describes our data and methods. The third presents our results, organised according to the three research questions outlined above. The final section outlines the limitations of this study and considers its implications for research and practice. 


\section{On children who repeatedly go missing}

Estimates vary on the extent to which children go missing repeatedly. This variation is partly attributed to the quality of available data and differences in how a repeat missing incident is defined. In relation to the former, a 2013 report argued that 'there is little or no reliable data on missing children ... [and] data on incidence reported by local authorities and that reported by the police are very significantly different' (OFSTED, 2013, p. 5). In relation to the latter, a recent assessment concluded that police services in England and Wales measure 'repeat missing' in different ways, with the most common definition being three or more disappearances in a 90 day period (HMIC, 2016). Mindful of inconsistencies in data and definition, previous studies suggest that between 29\% (Rees and Lee, 2005) and 64\% (Babuta and Sidebottom, 2018) of missing incidents involving children are repeats. This is typically higher than is observed for adults. For example, based on UK police data, $52 \%$ of all recorded missing incidents involving children were repeats compared with just $18 \%$ of those involving adults (NCA, 2016). Likewise, an analysis of nearly 6,000 missing incidents from the Thames Valley Police (UK) jurisdiction, found that children were significantly more likely to be reported missing twice or more than adults were over the six month study period (Vo, 2015). Indeed, of the 25 most frequently missing persons, 24 were children (Vo, 2015). Similar patterns are observed for non-police data. For example, the proportion of cases referred to the UK's Missing Persons Helpline where an individual had gone missing three times or more was substantially higher for those aged 24 years and under $(32 \%, n=593)$ than those aged 25 years or older (19\%, n=1,005) (Biehal et al. 2003). 
A recent study by Babuta and Sidebottom (2018) sought to quantify the extent of repeat disappearances by children. Using data from one mainly rural UK police service for the period January 2011 to May 2013, they found that the distribution of disappearances across young persons was heavily skewed, more so than would be expected on the basis of chance. While the majority of young people in their sample were reported missing once ( $n=392,58 \%), 15 \%$ were reported missing five times or more and together accounted for $53 \%$ of all incidents ( $\mathrm{n}$ $=1,001)$. Furthermore, children who went missing 10 times or more made up just $5 \%(n=35)$ of the sample but accounted for $30 \%$ of all missing incidents involving children $(n=573)$.

A small number of studies have investigated the characteristics, experiences and trajectories of children reported missing once compared with those reported missing twice or more. For example, Baker et al. (2003) collected longitudinal data on two cohorts of youths (repeat runaways and one-time runaways) accessing shelter services over a two-year period in one US city. They found that repeat runaways were more likely to be female and to report having experienced problems at school, higher levels of family conflict and higher levels of parental discipline. Using data from Victoria (Australia), Stevenson and Thomas (2018) report findings of a ten-year follow-up study of 215 randomly selected individuals aged 25 and under who were reported missing for the first time in 2005. Just over a third of participants $(n=74$, 34.4\%) went missing repeatedly. Those that did were more likely than individuals reported missing once to exhibit mental-health related vulnerabilities and to have higher offending rates (see also Shalev-Greene, 2011).

Research has also examined police attitudes towards children who frequently go missing. Drawing on interview data from nine UK police forces, Newiss $(1999, \mathrm{p} .7)$ observes how, 'the 
temptation for the police to view the report of a missing person as simply an administrative exercise would appear to be significantly increased when responding to repeat runaways'. Indeed, a recent inspection of UK police services concluded that children who persistently went missing and who did not want to engage with the police tended to be viewed as a 'time waster rather than a vulnerable child in need of help' (HMIC, 2016, p. 10). Consistent with this statement, Harris and Shalev Greene (2016) concluded that the customary return to home interviews and police 'Safe \& Well Check'ii are carried out with less rigour for repeat runaways than for those reported missing for the first time. They quoted one police officer as saying that, "after a child has gone missing three times, a return interview is a fairly pointless exercise' (Harris and Shalev Greene, 2016, p. 260).

In addition to studies focused specifically on missing children, other research has considered going missing within the context of various forms of abuse and exploitation. While the proportion of missing incidents linked to serious victimisation may be low (figures are not known at present), there is evidence suggesting a high rate of going missing among exploited children. For example, a study of over 9,000 children accessing Barnardo's support services for child sexual exploitation (CSE) in the UK found that over half were referred due to concerns around missing episodes (Cockbain et al. 2015). Numerous other studies and reports have emphasised a link between child sexual exploitation and going missing (e.g. CEOP, 2011; Jago et al., 2011; OCCE, 2012; Scott \& Skidmore, 2006; Sharp, 2012; Smeaton, 2013). As alluded to above, going missing is now widely regarded both as a risk factor for and an indicator of CSE (Sharp, 2012). Rather than necessarily 'running away' permanently, sexually exploited children may go missing for short periods on a regular basis (CEOP, 2011; OCCE, 2012). Recent years have also seen growing concern in the UK about so-called 'county lines' related criminal 
exploitation - in which children and other vulnerable people are used in the distribution, storage and sale of class-A drugs (see, e.g., Coomber \& Moyle, 2017; National Crime Agency, 2017a). Although the research literature on county lines is presently underdeveloped, going missing has been identified as both a potential indicator and a risk factor for 'county lines' related criminal exploitation (see, e.g., Crown Prosecution Service, 2017; National Crime Agency, 2017; The Children's Society et al., 2018). Finally, a study found that both trafficked children $(28 \%, n=167)$ and unaccompanied minors $(13 \%, n=593)$ went missing at high rates from local authority care in the UK in 2014-2015 (Simon, Setter and Holmes, 2016), raising concerns that these vulnerable children may be disappearing into exploitative situations (see also Beddoe, 2007; Child Exploitation and Online Protection Centre, 2010).

\section{The current study}

Data

One medium-sized, predominantly urban UK police service provided anonymised data on all missing person reports for the calendar year of 2015. Each entry included a unique identifier, the individuals' age, gender and ethnicity, the date and time they were last seen, their reported whereabouts whilst missing (e.g. stayed with friend, slept rough, not known), how they returned (e.g. found by the police/family, returned of their own accord) and whether they were in care at the time of disappearance. Also included were responses to nineteen (yes/no) questions concerning 'risk factors' associated with the missing person (Eales, 2017) ) $^{\mathrm{iii}}$. These questions are completed by the attending police officer(s) handling the missing person investigation. Questions covered the missing person's physical and mental capacity, perceived suicide risk, experience of family conflict and the circumstances of the 
disappearance (e.g. involvement in an altercation or harassment prior to going missing). From the information provided, we computed four additional variables: (1) the length of time a person was recorded as missing, (2) whether they had previously been reported missing within the 12 month study period (i.e. our definition of a repeat incident), (3) the total number of missing episodes per individual across the 12 month study period and (4) the length of time between missing episodes for those individuals reported missing more than once.

We excluded a small number of cases prior to analysis. These related mainly to duplicate cases and recording errors (e.g. when a person was recorded as being found on a date that preceded the date they were logged as missing). After removal, our final dataset contained 4,746 police recorded missing person incidents involving 2,516 individuals. In nearly three quarters of cases, the missing person was aged under 18. Put differently, although children constituted $53 \%$ of all individuals in our data $(n=1,331)$, they accounted for $71 \%$ of all missing person incidents $(n=3,352)$. The analyses that follow focus only on children.

Three features of our data warrant mention at this point. The first relates to children who go missing from care. In our data we were unable to differentiate between the different types of care arrangements available (i.e. local authority, voluntary sector, placements with wider family members, etc (see Hayden, 2017). The second relates to our assessment of repeat disappearances, and the so-called time-window effect (see Farrell, Sousa and Lamm-Wiesel, 2001). Simply put, we do not have information on whether children in our sample went missing before and/or after the one year period covered in this study. This likely undercounts the extent of repeat missing incidents involving children. Finally, it is important to note that the data used here do not include cases classified as 'absent', referring to persons whose 
whereabouts are unknown but who are considered to be at no apparent risk to themselves or others (ACPO, 2013). The category of absent was introduced to UK policing in 2013 , in part to help manage the high demand associated with investigating missing person reports (see Bayliss and Quinton, 2013). Whether an incident is classified as 'absent' or 'missing' is determined by the police call handler based on the information provided. Incidents classified as 'absent' do not require an immediate police response; incidents classified as 'missing' do, with the speed and intensity of response determined by the assessed level of risk: low, medium or high (see Eales, 2017). Instead, those cases marked as 'absent' are regularly reviewed and re-assessed for further risk. Force guidance states that no person under the age of 16 should remain classified as absent for longer than 15 hours. It is possible that some of the missing person cases within our dataset started out as 'absent' and were later upgraded to missing, though we do not have that information.

\section{Ethics statement}

The current study was reviewed and exempted by the [University name removed for review process] departmental ethics board on the basis that it used anonymous data from which no individuals were identifiable. Throughout the research, care was taken to maintain the security of the data. 


\section{Results}

\section{Descriptive statistics}

Table 1 (column 2) presents the characteristics of our entire sample of missing children. The mean age at time of first disappearance was $14(S D=2.6$; range $=0-17)$. The number of missing males is seen to be similar to that of missing females. Moreover, the majority of missing children were white (91\%), reflecting the demographic profile of the police force area (where around $90 \%$ of the total population self-identify as white). Over a quarter of missing children in our sample were recorded as having a history of family conflict (26.4\%), although details about the nature and type of such conflict were not available in the data used here. Moreover, consistent with previous research (Hayden, 2017), we find that a considerable proportion of missing children in our sample (43.7\%) were reported as being in care. To put this figure into context, according to British government statistics, there were just over 69,000 children in local authority care in England in 2015. That equates to a national rate of approximately 60 children in care per 10,000 children (although this rate varied across regions from 20 per 10,000 to 158 per 10,000). The same rate using our data on missing children is 4,732 per 10,000 children ${ }^{\text {iv }}$.

Turning to missing incidents, Table 1 shows that the majority of children were located within 24 hours of being reported missing ( $85.4 \%)$. In only $5 \%$ of cases was the child missing for more than one week. In roughly half of all incidents, the missing child returned of their own accord (47.0\%), while in just over a third (35.4\%) of incidents they were located by the police. A small number of cases $(n=52,1.6 \%$ ) resulted in the missing child being discovered as part of an 
arrest. This might be a survival strategy on the part of the missing child (i.e. arrested for shoplifting) or instances where they are victims of criminal exploitation, as is the case with the abovementioned county lines activity. Finally, a small but concerning minority of children were found in hospital ( $n=8,0.2 \%$ ) or harboured/abducted $(n=2,0.1 \%)$. The former typically relates to acts of self-harm whilst missing resulting in hospital admission.

\section{$<$ INSERT TABLE 1 ABOUT HERE >}

\section{On the extent of repeat child disappearances}

Table 2 shows the extent of repeat disappearances by children. It can be interpreted in several ways. First, it shows that $75 \%$ of missing incidents involving children were repeats, that is, missing episodes by children who had already been reported missing in 2015. Second, it shows that the distribution of disappearances is highly skewed among our sample of missing children. Most children ( $n=834 ; 62.7 \%$ ) were recorded as missing once in 2015. However, those children reported missing ten times or more $(n=59)$ made up under $5 \%$ of our sample of missing children but accounted for almost $30 \%$ of all missing incidents involving children $(28.4 \%)^{\mathrm{v}}$.

$<$ INSERT TABLE 2 ABOUT HERE>

Following Babuta and Sidebottom (2018), we assume that it is not by chance that some children go missing more often than others. Drawing on previous research on repeat victimisation (see for e.g. Sagovsky and Johnson, 2007), this was examined by assessing 
whether the observed number of children reported missing one to ten or more times was sufficiently different to a Poisson distribution. Column four of Table 2 shows that the number of children who went missing ten times or more was much greater than would be expected by chance. A chi-square test confirmed that the difference between the observed and expected frequency of missing episodes per child was statistically significant, $\chi^{2}(9)=12072$, $p<.001$ ), lending support to the notion that children who have been reported missing once exhibit a greater likelihood of being reported missing again ${ }^{\mathrm{vi}}$.

\section{On the characteristics of children who repeatedly go missing}

Having established the extent of repeat missing incidents involving children, we then explored the characteristics of children who, over the one year study period, were reported missing once, two to nine times or ten times or more. Percentages across the three groups are shown in Table 1 (columns 3 to 5). Chi-square tests revealed significant associations between these groups and the variables 'being in care', $\left.x^{2}(2, n=1,331)=94.02, p<.0001\right)$ and 'drug or alcohol dependency', $\left.x^{2}(2, n=1,331)=11.09, p<.005\right)$. The proportion of children in care was around 2.5 times higher among those reported missing ten times or more (83\%) compared to children reported missing once (34\%). The proportion of children with recorded drug or alcohol dependencies was, although still low, three times higher among those reported missing ten times or more (12\%) than those reported missing once (4\%). Differences between the remaining variables were not statistically significant.

Table 3 shows these relationships in a slightly different way. Statistics are presented as odds ratios with one-time missing children acting as the reference group. It can be seen that 
children missing ten times or more were over three times more likely to exhibit drug or alcohol dependencies, over four times as likely to be teenagers and nine times more likely to be in care compared to children who went missing once. The same pattern held when comparing one-time missing children with those who went missing two to nine times, but the magnitude of the effect in each case was reduced. The analysis was repeated to compare children who went missing two to nine-times and those missing on ten or more occasions (analyses not shown). Only one variable was found to be statistically significant: being in care $(\mathrm{OR}=3.82, \mathrm{Cl}=1.89-7.75, p<.05)$.

\author{
<INSERT TABLE 3 ABOUT HERE>
}

\title{
The time course of repeat missing incidents involving children
}

The results above suggest that going missing in the past may be a reliable predictor of going missing in the future. A limitation of our analyses thus far is that it covers the entire calendar year of 2015. No indication is hence provided as to when the risk of a repeat disappearance is greatest, and for how long risk may be elevated. To explore this question, we again draw on the repeat victimisation literature, where extensive research across a range of crime types suggests that following an initial victimisation, the risk of being revictimised is heightened and decays quickly over time (Chenery et al. 1997; Polvi et al. 1990; Sagovsky and Johnson, 2007; Townsley et al. 2000). As indicated previously, to date, the temporal patterns of missing incidents involving children has received limited research attention. Prior research has tended to look at the duration of missing episodes as opposed to the time elapsed between repeat disappearances. Both kinds of temporal research have implications for practice. Whilst 
research evidence on the duration of missing episodes is important for investigation purposes, we contend that research on the time-to-repeat can usefully inform police and partner efforts to prevent subsequent (repeat) disappearances. To this aim, our final analysis examines the time course of repeat disappearances.

Before proceeding, it is important to address two limitations which have been discussed in relation to the time course of repeat victimisation but which are also germane to repeat disappearances by children. Both concern issues of aggregation. The first is the tendency to measure the time course of repeat victimisation by pooling together all revictimisations experienced by the population of interest (be it people or properties). Doing so means that, say, individuals that experience three of more victimisations over a given time period will necessarily contribute two or more observations to the analysis. It follows that the aggregated time course of revictimisation using such data may be skewed to reflect the time course of those individuals who were victimised most frequently. To overcome this, Sagovsky and Johnson (2007) recommend analysing only the time to first revictimisation, with each victim therefore contributing only one victimisation to the data being analysed. This study similarly only analyses the time to first repeat disappearance (i.e. the time elapsed between a child's first and second police recorded missing episode).

The second limitation relates to heterogeneity in risk. In the case of burglary, for example, it is well-known that owing to the design of households or the behaviour of occupants, some properties exhibit a higher risk of burglary than others (see Tseloni, 2006). It follows that across any time period, all things being equal, those households with features known to confer a greater risk of victimisation would be expected to be revictimised faster than low- 
risk households. As above, Sagovsky and Johnson (2007) argue that the aggregated distribution might therefore reflect the time course associated with the revictimisation of high risk properties as opposed to the population more generally. To overcome this, they suggest that the time course of repeat victimisation be analysed separately for populations where evidence indicates differential levels of risk. In their study, for example, they assessed the time course for households revictimised once and those revictimised twice or more. Here, informed by prior research and the findings described above, we analyse the time-to-first repeat disappearance separately for children in care verses those not in care.

Figure 1 presents the time course of first repeat disappearances by children. It indicates that the risk of going missing a second time decays swiftly over the two months following an initial missing episode. In both groups, roughly half of all first repeats occurred within four weeks of an initial disappearance (in care $=59.2 \%$, not in care $=53.4 \%$ ). vii The count of repeat disappearances per week following an initial missing incident was significantly correlated across the two groups $(r=0.90, n=52, p<.001)$, indicating that the temporal signature of time to first disappearance was similar whether a child was in care or not.

\section{< INSERT FIGURE 1 ABOUT HERE >}

\section{Discussion}

Responding to reports of missing children is an everyday occurrence for the police in the UK. It is a leading source of police demand. Protecting missing children is not only a priority for the police but also a public health concern, in light of emerging evidence that missing children 
may be at heightened risk of abuse, exploitation and harm. Despite this, relatively little is known about the prevalence and temporal patterns of repeat child disappearances, as well as the characteristics of those involved. This study, informed by research and theory on repeat victimisation, set out to examine (1) the extent of repeat disappearances by children, (2) the characteristics of children who go missing more frequently than others, and (3) the time course of repeat disappearances.

The present analysis found a high volume of repetition. Repeat missing episodes constituted $75 \%$ of all police recorded missing incidents involving children over the one year study period. This is markedly higher than is typically found for repeat victimisation - normally in the order of $40 \%$ (Farrell, Tseloni and Pease, 2005) - and represents the sizable proportion of missing incidents that might, in theory, be reduced if repeat disappearances by children were prevented. Our results also indicated that missing incidents were highly concentrated across our sample of missing children. While the majority of children $(n=834 ; 62.7 \%)$ were recorded as missing once over the 12 month study period, 59 children (4.4\%) were recorded as being missing ten times or more and accounted for $28.4 \%(n=952)$ of all police recorded missing child incidents. From a safeguarding perspective, there are obvious grounds to believe that these chronically missing children may be at greater risk of harm (broadly defined). Moreover, from an economic perspective, their recurrent disappearances exact considerable investigation costs. Using the average cost per missing episode proposed by Shalev Greene and Pakes $(2013=£ 2,415.80)$, this group of 59 children accounted for an estimated police expenditure of $£ 2.29$ million over the one year study periodviii. 
It is noteworthy that the level of concentration observed in this study closely resembles that reported by Babuta and Sidebottom (2018), where $5.2 \%$ of children who went missing ten times or more accounted for $30.4 \%$ of all child disappearances. Although two localised studies is too limited a basis to assume generalisability, the similarities between the results may be suggestive of a wider pattern deserving of further research. In the interests of inviting falsification, we hypothesise that in any sample of missing children, a small proportion of repeatedly missing children will account for a sizable proportion of all missing child incidents. If generalisable, these concentration patterns may hold important opportunities for intervention. There is now extensive evidence on the benefits of allocating preventive resources to those victims and places where crime is shown to concentrate (see for e.g. Grove, Farrell, Farrington and Johnson, 2012). The findings of this study suggest that the same might apply to missing children, namely that preventive gains (social, health and economic in nature) might be maximised by focussing efforts on the small number of children who go missing repeatedly. Of course, advocating targeted prevention of this nature should not detract from taking all incidents of children going missing seriously and responding to their unique circumstances. Moreover, knowledge about where resources might sensibly be targeted says nothing about the sorts of interventions that might be put in place, and whether differing levels of repetition requires a different type and intensity of response (akin to the 'graded' response sometimes implemented to reduce repeat victimisation, see Anderson et al. 1995). In this respect, regrettably, there are very few interventions that have been shown to effectively reduce repeat missing episodes involving children (for a recent review of the evidence on police response to missing persons, see Giles, 2017). 
On comparing children who were recorded missing once, two to nine times and ten times or more across various characteristics, two findings are considered noteworthy. The first concerns the relationship between being in care and going missing repeatedly. Previous research converges on the finding that children in care are overrepresented in missing persons data (Hayden and Goodship, 2013; Hayden and Shalev Greene, 2018; Hayden, 2017; Rees, 2011). This finding comes with two qualifiers: (1) children going missing from care may have also gone missing before their care placement, thereby suggesting that "care" is not causally related to going missing and (2) the high frequency of disappearances by children in care may reflect reporting procedures whereby carers are obliged to contact the police when the whereabouts of a child within their care is unknown (sometimes referred to as 'quick calling'; see Newiss, 1999; Simon et al. 2016). These qualifiers notwithstanding, in this study we also find that the proportion of children in care was significantly higher among those reported missing ten times or more (83\%) than for children recorded as missing on two to nine occasions (56\%) or only once (34\%).

The second noteworthy finding relates to drug or alcohol dependency. Children in this study who went missing ten times or more exhibited significantly higher levels of recorded drug or alcohol dependencies (12\%) than children who went missing once only (4\%). Regrettably, our data do not allow us to determine if and how drug and alcohol dependencies are causally related to a child (repeatedly) going missing. Moreover, possible inconsistences in what is and isn't reported to the police may affect the reliability of these findings. However, if such problems are characteristic of children who persistently go missing, it suggests that efforts to reduce repeat child disappearances might usefully incorporate drug and/or alcohol abuse programmes. Likewise, early intervention programmes oriented towards safeguarding 
vulnerable children might include drug and alcohol dependencies as a possible risk factor for going missing. In the literature on CSE, a common theme is that children can be manipulated into sexual abuse using drugs/alcohol and/or turn to them to cope with the associated trauma (see, e.g. Cockbain, 2018; OCCE, 2012). Consequently, the higher prevalence of substance abuse among repeatedly missing children gives additional cause for concern about these individuals' welfare. Of course, the suggestion of potential links to exploitation is only one of several possible explanations for the patterns observed and should not be overstated.

The final part of our analysis examined the time-to-first repeat. It is interesting that the observed time course is similar to that routinely found for repeat victimisation, whereby the risk of repeat victimisation is elevated following an initial victimisation and decays over time. In the context of this study, over half of all first-repeats were found to occur within four weeks of an initial disappearance. This pattern held for children that were in care and those that were not. As the first analysis of this kind in relation to missing children, the representativeness of these results is uncertain. If generalisable, however, this pattern may hold both theoretical and preventive implications. From a theoretical perspective, it is useful to consider why repeat missing episodes exhibit such temporal patterns. For repeat criminal victimisation, the frequently observed time course is explained in terms of event dependence (the boost account) and risk heterogeneity (the flag account), and interactions between the two (see Farrell and Pease, 2017). Something similar might also apply here: some aspect of a prior missing episode might increase the likelihood of a child going missing again (boost account), likewise some factor(s) at the child's home might remain unchanged thereby propelling them to go missing again. From a prevention perspective, the time course pattern observed here suggests that efforts to reduce recurrent disappearances by children may need 
to be put in place shortly after (within four weeks) a child has returned home. The same is true of Return to Home Interviews, if the intention is to elicit information that might inform a police and/or partner response. To this end, useful insights can again be gleaned from the repeat victimisation literature, which contains multiple case studies on the processes for and challenges of responding quickly in a bid to reduce the demonstrable time-elevated risk of repeats (see for e.g. Chenery et al. 2002; Fielding and Jones, 2012; Johnson et al. 2017).

Finally, the limitations of this study are acknowledged and suggestions of some might be addressed in future research are provided. First, there is the familiar problem of underreporting. Not all missing incidents are reported to the police (Rees and Lee, 2005). Consequently, the figures reported here may underestimate the true scale of (repeat) child disappearances. Anecdotally, there are reports that some parents and guardians may give up reporting children as missing if they perceive the police response to be ineffective. Second, the accuracy of information provided in response to the risk factor questions could not be verified (for e.g. the presence of drug or alcohol dependencies). Again, it is possible that there is a degree of underreporting in relation to such questions. A third limitation, mentioned previously, is our inability with the data available to differentiate between or within different types of child care arrangements. In relation to the latter, absence of geographic information meant we were unable to analyse the distribution of missing incidents across comparable care settings (i.e. local authority care homes), as is commonly practiced in the crime analyses literature (see the work of Eck et al. 2007 on so-called 'risky facilities'). This is a promising area for future research. Related to this, we did not have information on children whose repeat disappearances may have contributed to them being placed in a care setting outside of the police jurisdiction for which we have data, as sometimes occurs because of 
safeguarding concerns (DfE, 2014; Eaton, 2019). Such practices would mean that the extent of repeat disappearances would be understated.

Fourth, the dataset used here was not designed for research purposes. Numerous factors that would have been of research interest, relating to both the individual (i.e. being bullied, truanting or youth offending) and the environment from which they went missing (i.e. number of staff in care home) were hence not recorded. Similarly, we did not have information on the destination that children went missing to. For operational purposes, it would be useful to determine if repeatedly missing children always went to the same location. This could be explored in future research. Finally, throughout this analysis, independence of observations has been assumed. More specifically, we assumed that all children in our sample are independent. In reality, it is plausible that some children go missing in part because of their exposure to and interactions with other children who have gone missing (Babuta and Sidebottom, 2018). This relationship is challenging to test quantitatively using police data as often little information is available at scale on the links between individuals. Using individual case files can offer insights and has led to identification (albeit on a small scale) of how young people's peer relations can spread and sustain CSE, for example (Cockbain, 2018). Elsewhere, large-scale arrest data on co-offending has been used to examine how homicide victimisation concentrates among linked individuals within high-risk communities (Papachristos and Wildeman, 2014). Social network analysis is an area where future research might usefully be directed to examine the strength and role of peer effects in children who go missing repeatedly. 


\section{References}

ACPO. (2010). Guidance on the management, recording and investigation of missing persons (2nd ed.), Available online at: http://library.college.police.uk/docs/npia/missingpersons-guidance-2010.pdf

ACPO (2013). Interim guidance on the management, recording, and investigation of missing persons 2013. Available online at:

http://library.college.police.uk/docs/college-of-policing/Interim-Missing-Persons-Guidance2013.pdf

Anderson, D., Chenery, S., \& Pease, K. (1995). Preventing repeat victimisation: A report on progress in Huddersfield. London, UK: Home Office.

Babuta, A., \& Sidebottom, A. (2018). Missing Children: On the Extent, Patterns, and Correlates of Repeat Disappearances by Young People. Policing: A Journal of Policy and Practice. https://doi.org/10.1093/police/pay066

Baker, A. J., McKay, M. M., Lynn, C. J., Schlange, H., \& Auville, A. (2003). Recidivism at a shelter for adolescents: First-time versus repeat runaways. Social Work Research, 27(2), 84-93.

Bayliss, A., \& Quinton, P. (2013). Risk, bureaucracy and missing persons: An evaluation of a new approach to the initial police response. Ryton: College of Policing.

Beddoe, C. (2007). Missing Out: A Study of Child Trafficking in the North-West, North-East and West Midlands. London: E. UK.

Biehal, N., Mitchell, F., and Wade, J. (2003). Lost from View: Missing Persons in the UK. Bristol: Policy Press.

Bricknell, S. \& Renshaw, L. (2016). Missing persons in Australia, 2008-2015. Australian Institute of Criminology.

CEOP (Child Exploitation and Online Protection Centre). (2011). The trafficking of women and children from Vietnam London: CEOP.

Chenery, S., Holt, J., \& Pease, K. (1997). Biting back II: Reducing repeat victimisation in Huddersfield (Crime Detection and Prevention Series, Paper 82). London: Home Office.

Chenery, S., C. Henshaw, \& K. Pease. 2002. Repeat victimisation and the policing ocommunities. International Review of Victimology 9: 137-148.

Children's Society, Victim Support, \& The National Police Chief's Council. (2018). Children and young people trafficked for the purpose of criminal exploitation in relation to county lines: A toolkit for professionals. London: The Children's Society. 
Cockbain, E. (2018). Offender and Victim Networks in Human Trafficking. Abingdon: Routledge.

Cockbain, E., Ashby, M., \& Brayley, H. (2015). Immaterial boys? A large-scale exploration of gender-based differences in child sexual exploitation service users. Sexual abuse: a journal of research and treatment, 29(7), 658-684.

Coomber, R., \& Moyle, L. (2017). The changing shape of street-level heroin and crack supply in England: Commuting, holidaying and cuckooing drug dealers across 'County lines'. The British Journal of Criminology, 58(6): 1323-1342.

Crown Prosecution Service. (2017). 'County lines': typology. London: C. P. Service.

College of Policing. (2015). College of Policing Analysis: Estimating Demand on the Police Service. Available online at:

http://www.college.police.uk/News/Collegenews/Documents/demand\%20Report\%2023 115 noBleed.pdf

Department for Education (2014). Statutory guidance on children who run away or go missing from home or care. Available online at: https://assets.publishing.service.gov.uk/government/uploads/system/uploads/attachment data/file/307867/Statutory Guidance - Missing from care 3 .pdf

Eales, N. (2017). Risk assessment. In K.Shalev-Greene, \& L. Alys. (Eds.) Missing Persons: A Handbook of Research. Abingdon, Oxon; New York, NY: Taylor \& Francis.

Eaton, J. (2019). The human rights of girls subjected to child sexual exploitation in the UK. Available online at: https://irpcdn.multiscreensite.com/f9ec73a4/files/uploaded/The\%20Human\%20Rights\%20of\%20Girls \%20Subjected\%20to\%20CSE\%20EATON2019.pdf

Farrell, G. (1995). Preventing repeat victimization. Crime and Justice, 19: 469-534.

Farrell, G., \& Pease, K. (2017). Preventing repeat and near repeat crime concentrations. In N. Tilley and A. Sidebottom (eds.) Handbook of Crime Prevention and Community Safety. London: Routledge.

Farrell, G. Sousa, W.H. \& Lamm Weisel. D. (2002). The time-window effect in the measurement of repeat victimization: A methodology for its examination, and an empirical study. Crime Prevention Studies 13: 15-27.

Farrell, G., Tseloni, A., \& Pease, K. (2005). Repeat victimization in the ICVS and the NCVS. Crime Prevention and Community Safety, 7(3), 7-18.

Fielding, M. \& V. Jones. (2012). Disrupting the optimal forager: Predictive risk mapping and domestic burglary reduction in Trafford, Greater Manchester. International Journal of Police Science and Management 14 (1): 30-41. 
Fyfe, N. R., Stevenson, O., and Woolnough, P. (2015). Missing Persons: The Processes and Challenges of Police Investigation. Policing \& Society 25(4): 409-425.

Giles, S. (2017). Rapid Evidence Assessment: 'What Works' in Police Response to Missing Persons? Report produced for West Midlands Police.

Government of Canada: National Centre for Missing Persons and Unidentified Remains (2017). Canada's missing - 2017 fast fact sheet. Available online at: http://www.canadasmissing.ca/pubs/2017/index-eng.htm

Grove, L. E., Farrell, G., Farrington, D. P., \& Johnson, S. D. (2012). Preventing repeat victimization: A systematic review. Brottsförebyggande rådet/The Swedish National Council for Crime Prevention.

Harris, M. F., \& Shalev Greene, K. (2016). Police attitudes in England to return interviews, in repeat missing person cases. Journal of Investigative Psychology and Offender Profiling, 13(3), 253-266.

Hayden, C. \& Shalev-Greene, K. (2018) The blue light social services? Responding to repeat reports to the police of people missing from institutional locations, Policing and Society, 28:1, 45-61.

Hayden, C. (2017). 'Children Missing from Care'. In K. Shalev- Greene K. and L. Alys. (eds.). Missing Persons: A Handbook of Research. Abingdon, Oxon; New York, NY: Taylor \& Francis.

Hayden, C., \& Goodship, J. (2013). Children reported 'missing'to the police: is it possible to 'risk assess' every incident?. The British Journal of Social Work, 45(2), 440-456.

Hayden, C. and Shalev Greene, K. (2018). 'The Blue Light Social Services? Responding to Repeat Reports to the Police of People Missing from Institutional Locations'. Policing and Society 28(1): 45-61.

Heerde, J. A., Hemphill, S. A., \& Scholes-Balog, K. E. (2014). 'Fighting' for survival: A systematic review of physically violent behavior perpetrated and experienced by homeless young people. Aggression and violent behavior, 19(1), 50-66.

Henderson, M. \& Henderson, P. (1998) Missing People: Issues for the Australian Community. Australian Bureau of Criminal Intelligence, Canberra.

Holmes, L. (2008). Living in Limbo. The experience of, and impact on, the families of missing people. Available online at:

http://www.missingpeople.org.uk/files/Research\%20publications\%20and\%20presentations Living in Limbo 2008.pdf

Holmes, L. (2017). Resolution of missing incidents. In K. Shalev- Greene K. and L. Alys. (eds.). Missing Persons: A Handbook of Research. Abingdon, Oxon; New York, NY: Taylor \& Francis. 
HMIC (2015). In Harm's Way: The Role of the Police in Keeping Children Safe. Inspecting Policing in the Public Interest. Available online at: https://www.justiceinspectorates.gov.uk/hmicfrs/wp-content/uploads/in-harms-way.pdf

Jago, S., Arocha, L., Brodie, I., Melrose, M., Pearce, J., \& Warrington, C. (2011). What's going on to safeguard children and young people from sexual exploitation? How local partnerships respond to child sexual exploitation. Luton: U. o. Bedfordshire.

Johnson, S.D., T. Davies, A. Murray, P. Ditta, J. Belur, \& K. Bowers. 2017. Evaluation of operation swordfish: A near-repeat target-hardening strategy. Journal of Experimental Criminology, 13 (4): 505-525.

ONS (2016). Crime in England and Wales: year ending Mar 2016.

National Crime Agency (2016). Missing Persons Data Report 2014/15. London: NCA.

National Crime Agency. (2017). County Lines Violence, Exploitation \& Drug Supply. London: NCA.

Newiss, G. (1999), Missing Presumed .. .? the Police Response to Missing Persons. Police Research Series Paper 114. London: Home Office.

OCCE (Office of the Children's Commissioner for England) (2012). 'I thought I was the only One in the world.' The Office of the Children's Commissioner's inquiry into child sexual exploitation in gangs and groups, interim report. London: OCCE.

Ofsted, 2013. Missing children. Available online at: http://www.ofsted.gov.uk/resources/missing-children

Papachristos, A. V., \& Wildeman, C. (2014). Network exposure and homicide victimization in an African American community. American journal of public health, 104(1), 143-150.

Pease, K. (1998). Repeat victimisation: Taking stock (Vol. 90). London: Home Office Police Research Group.

Police Scotland (2018). Missing persons: Annual report 2017/18. Available online at: https://www.scotland.police.uk/assets/pdf/174967/ps-missing-persons-annual-report2017-18?view=Standard

Polvi, N., Looman, T., Humphries, C., \& Pease, K. (1991). The time course of repeat burglary victimisation. British Journal of Criminology, 31(4), 411-414.

Rees, G. (2011). Still Running 3. London: The Children's Society.

Rees, G. and Lees, J., 2005. Still running II: findings from the second national survey of young runaways. London: The Children's Society. 
Sagovsky, A. and Johnson, S. D. (2007). 'When Does Repeat Burglary Victimisation Occur?' Australian \& New Zealand Journal of Criminology 40(1): 1-26.

Scott, S. and Skidmore, P. (2006). Reducing the risk: Barnardo's support for sexually exploited young people - A two-year evaluation. London: Barnardo's.

Sharp, N. (2012). Still Hidden? Going missing as an indicator of child sexual exploitation. London: Missing People.

Shalev Greene, K. (2011). 'Children Who Go Missing Repeatedly and Their Involvement in Crime'. International Journal of Police Science and Management 13(1): 2936.

Shalev Greene, K., \& Pakes, F. (2013). The cost of missing person investigations: Implications for current debates. Policing: A Journal of Policy and Practice, 8(1), 27-34.

Sharp-Jeffs, N. (2016), 'Going Missing as an Indicator of Child Sexual Exploitation'. In ShalevGreene, K. and Alys L. (eds) Missing Persons: A Handbook of Research. Taylor \& Francis.

Simon, A., Setter, C., and Holmes, L. (2016). Heading Back to Harm: A Study on Trafficked and Unaccompanied Children Going Missing from Care in the UK. Available online at:

https://www.ecpat.org.uk/heading-back-to-harm-a-study-on-trafficked-andunaccompanied-children-going-missing-from-care-in-the-uk

Smeaton, E. (2013). Running from hate to what you think is love: the relationship between running away and child sexual exploitation. London: Barnardo's.

Stevenson, E., \& Thomas, S. D. (2018). A 10 year follow-up study of young people reported missing to the police for the first time in 2005. Journal of Youth Studies, 21(10), 1361-1375.

Townsley, M., Homel, R., \& Chaseling, J. (2000). Repeat burglary victimisation: Spatial and temporal patterns. Australian and New Zealand Journal of Criminology, 33(1), 37-63.

Tseloni, A. (2006). Multilevel modelling of the number of property crimes: household and area effects. Journal of the Royal Statistical Society: Series A (Statistics in Society), 169(2), 205-233.

Vo, Q. T. (2015). 6000 cases of missing and absent persons: patterns of crime harm and priorities for resource allocation. Dissertation submitted as part of the Master's Degree in Applied Criminology and Police Management, University of Cambridge. Available online at: https://www.crim.cam.ac.uk/alumni/available-theses

Wade, J., Biehal, N., Clayden, J., and Stein, M. (1998). Going Missing: Young People Absent from Care. West Sussex: John Wiley and Sons.

Wayland, S. (2007). Supporting those who are left behind: A counselling framework to support families of missing persons. Australian Federal Police. 
Whitbeck, L. B., Hoyt, D. R., Johnson, K. D., \& Chen, X. (2007). Victimization and posttraumatic stress disorder among runaway and homeless adolescents. Violence and victims, 22(6), 721-734. 


\section{ENDNOTES}

i According to the National Crime Agency, there were 242,317 police recorded missing person incidents in England and Wales in 2015/16. By way of comparison, over the same time period the police recorded 193,773 domestic burglary offences and 45,483 robbery of personal property offences (ONS, 2016).

ii Return to home interviews are designed to help understand why a child has gone missing, identify harm and help them feel safe. They are conducted by an independent, trained professional, whereas Safe and Well checks are conducted by the police, to locate vulnerable people at risk of harm in order to safeguard them. iii These questions are derived from the College of Policing's Decision-Making Guide (2009) available online at: http://library.college.police.uk/docs/APPREF/Decision-making-guide-2009.doc iv $582 / 1331 * 10000$.

$\checkmark$ The most prolific individual was recorded as going missing forty one times in 2015.

vi We performed the same analysis for boys and girls separately and observed similar results (available from the authors on request).

vii It is important to note that initial disappearance, as defined herein, need not denote first disappearance. Some children may have been reported missing at some point in time that predates this study period. Initial, for the purposes of this study, refers to the first disappearance reported during the calendar year of 2015.

viii This is likely to be a conservative estimate, for two reasons. First, the cost estimate computed by Shalev Greene and Pakes (2013) relates to a medium-risk medium-term missing persons case. Of the 952 incidents associated with our chronically missing group (children who went missing 10 times or more in the one year study period), fifty (5\%) were categorised as high risk. These investigations likely cost considerably more than $f 2,415.80$. Second, this estimate does not include the costs imposed on partner agencies affected by missing person incidents. For example, local authorities who undertake return to home interviews. 
Tables

Table 1. Descriptive statistics

\begin{tabular}{lrrrr}
\hline Characteristics & $\begin{array}{r}\text { Full } \\
\text { sample }\end{array}$ & $\begin{array}{r}\text { Missing } \\
\text { once }\end{array}$ & $\begin{array}{r}\text { Missing two } \\
\text { to nine times }\end{array}$ & $\begin{array}{r}\text { Missing ten } \\
\text { times or more }\end{array}$ \\
\hline Individuals & $(n=1,331)$ & $(n=834)$ & $(n=438)$ & $(n=59)$ \\
Age (mean) & 14.1 & 13.8 & 14.5 & 14.5 \\
Sex (\% male) & 51.9 & 52.6 & 50.6 & 52.5 \\
Ethnicity (\% white) & 91.3 & 90.8 & 92.0 & 93.2 \\
In care (\%) & 43.7 & 34.4 & 56.2 & 83.1 \\
History of family conflict (\%) & 26.4 & 26.9 & 25.6 & 27.1 \\
Health concerns (\%) & 15.6 & 17.0 & 13.7 & 10.2 \\
Drug/alcohol dependency (\%) & 5.0 & 3.7 & 6.6 & 11.9 \\
& & & & \\
Incidents & $(n=3,352)$ & $(n=834)$ & $(n=1566)$ & $(n=952)$ \\
& & & & \\
Returned <24 hrs (\%) & 85.4 & 90.9 & 85.4 & 80.8 \\
Returned >24 but <48 hrs (\%) & 8.9 & 5.9 & 9.6 & 10.5 \\
Returned $>$ 48hrs but <1 week (\%) & 5.0 & 2.5 & 4.5 & 7.8 \\
Returned of own accord (\%) & 47.0 & 44.5 & 47.6 & 48.3 \\
Found by police (\%)** & 35.4 & 35.7 & 36.3 & 33.7 \\
\hline
\end{tabular}

NOTE: nationality was not available in our data.

* Both physical and mental

**Remaining entries on how the missing child was returned (in descending order) are 'found by family/carer' (11.4\%), 'not known/other' (4.3\%), 'arrested' (1.6\%), 'found in hospital' $(0.2 \%)$ and 'found harboured and/or abducted' (0.1\%) 
Table 2: Observed and expected distribution of police recorded disappearances involving children

\begin{tabular}{lrrr}
\hline No. of disappearances & $\begin{array}{r}\text { Observed no. (\%) } \\
\text { of children }\end{array}$ & $\begin{array}{r}\text { Observed no. (\%) of } \\
\text { incidents }\end{array}$ & $\begin{array}{r}\text { Expected no. of } \\
\text { children* }\end{array}$ \\
\hline 1 & $834(62.7)$ & $834(24.9)$ & 294 \\
2 & $173(13.0)$ & $346(10.3)$ & 370 \\
3 & $97(7.3)$ & $291(8.7)$ & 311 \\
4 & $64(4.8)$ & $256(7.6)$ & 196 \\
5 & $38(2.9)$ & $190(5.7)$ & 99 \\
6 & $21(1.6)$ & $126(3.8)$ & 41 \\
7 & $17(1.3)$ & $119(3.6)$ & 15 \\
8 & $14(1.0)$ & $112(3.3)$ & 5 \\
9 & $14(1.1)$ & $126(3.8)$ & 1 \\
10 or more & $59(4.4)$ & $952(28.4)$ & $<1$ \\
\hline Total & $1,331(100)$ & $3,352(100)$ & \\
*calculated using Poisson distribution & & & \\
\hline
\end{tabular}


Table 3: Comparison of the characteristics of one-time missing children and those missing on two to nine occasions and on ten or more occasions

\begin{tabular}{lll}
\hline Variables & $\begin{array}{l}\text { Missing two to nine } \\
\text { times }(n=438)\end{array}$ & $\begin{array}{l}\text { Missing ten times or } \\
\text { more }(n=59)\end{array}$ \\
& OR $(95 \% \mathrm{Cl})$ & OR $(95 \% \mathrm{Cl})$ \\
\hline Age (teenage)\# & $2.55(1.76-3.71)^{*}$ & $4.54(1.40-14.69)^{* *}$ \\
Sex (\% male) & $1.09(0.86-1.37)$ & $1.00(0.59-1.70)$ \\
Ethnicity (\% white) & $1.17(0.77-1.78)$ & $1.40(0.49-3.96)$ \\
In care at time of disappearance (\%) & $2.44(1.93-3.09)^{*}$ & $9.34(4.66-18.71)^{*}$ \\
History of family conflict (\%) & $1.07(0.82-1.39)$ & $0.99(0.54-1.79)$ \\
Physical/mental health concerns (\%) & $1.29(0.93-1.79)$ & $1.81(0.76-4.30)$ \\
Drug or alcohol dependency (\%) & $1.84(1.09-3.09)^{* *}$ & $3.49(1.47-8.30)^{* *}$
\end{tabular}

NOTE: children missing once act as reference group

\# Age is operationalised here as a binary variable $(0=0-12$ years of age, $1=13-17$ years of age $)$

** Significant to a $p<.01$ level.

* Significant to a $p<.05$ level. 


\section{Figure}

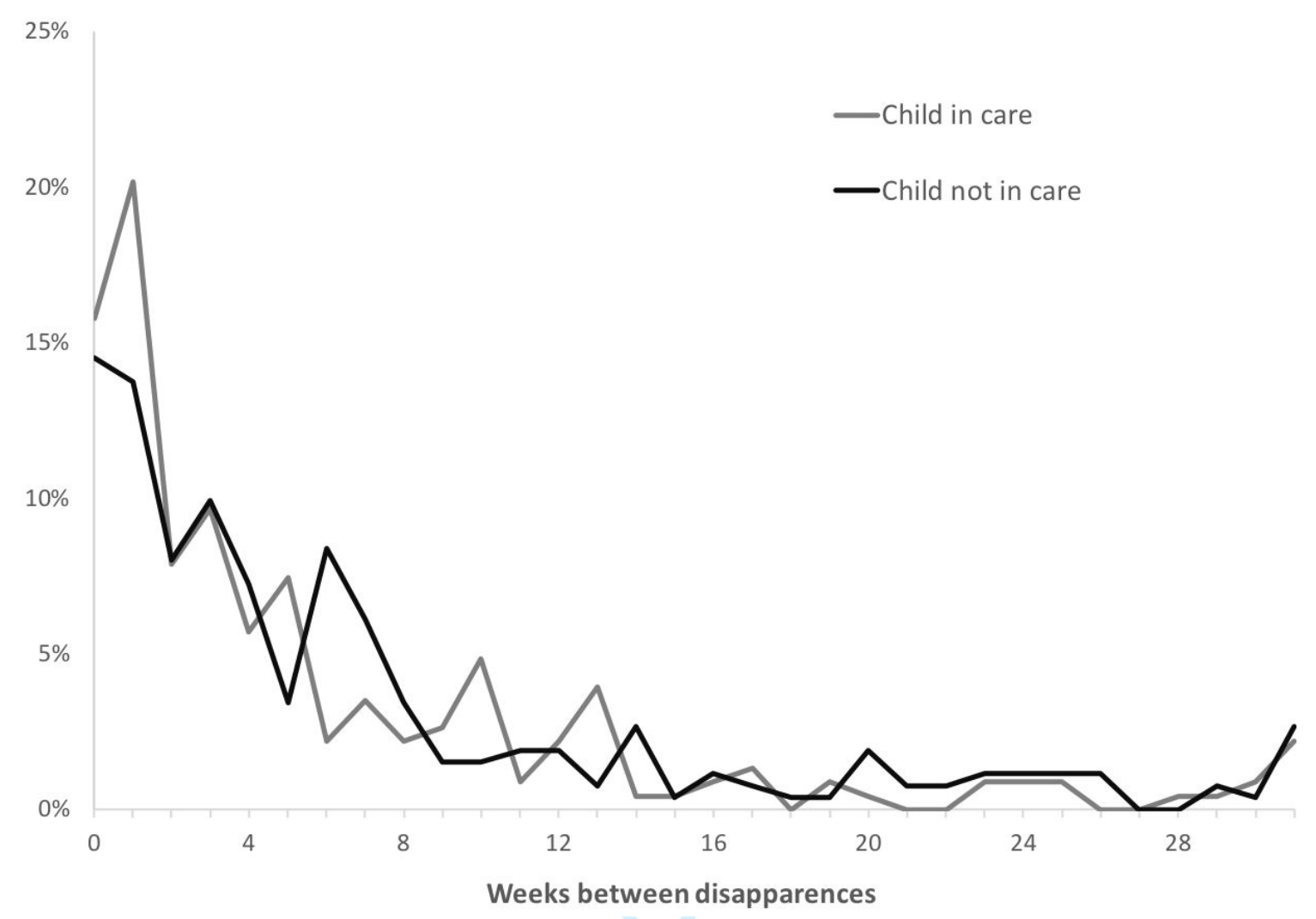

Figure 1 Time-to-first repeat disappearance by children in care and not in care, 2015 